Research Article

\title{
CONDENSATION ANALYSIS OF THE INSULATION OF WALLS IN MARDIN PROVINCE ACCORDING TO DIFFERENT LOCATIONS
}

\author{
Fatih $U N A L^{1 *}$
}

\begin{abstract}
In this study, condensation and vapor diffusion caused by different positioned insulation in the wall were analyzed for Mardin province. In the analysis, according to the 2008 standard of TS 825, the MATLAB calculation program was used with the Glaser graphing method and graphical user interface (GUI). Extruded polyurethane foam was used as the insulation material and normal unreinforced concrete was chosen as the wall. Evaporation and condensation values were determined by creating 6 different wall models with the same insulation thickness of $20 \mathrm{~cm}$ and an unreinforced concrete wall was covered with $2 \mathrm{~cm}$ plaster on the inside with a $3 \mathrm{~cm}$ thickness on the outside. The data obtained for $2 \mathrm{~cm}$ and $4 \mathrm{~cm}$ insulation thicknesses are presented in tables and the results are interpreted for Mardin province. Consequently, it was seen that the worst wall structure in terms of condensation and evaporation was obtained in the middle insulated wall and later in the interior insulated wall structure. The externally insulated wall did not show any condensation.
\end{abstract}

Keywords: Condensation and vapor diffusion, Glaser graphic method, TS 825 Standard, Insulation

\section{Introduction}

Turkey is a foreign dependent country in terms of energy sources. Therefore, any kind of energy efficiency research has great importance for our country. If insulation materials are used correctly and in sufficient quantities, materials, energy, and costs will be saved [1]. The outer walls of the buildings, which form a border between the interior spaces, remain under the influence of constantly changing climatic conditions. In order to provide comfort conditions according to the changing climatic conditions, it is necessary to insulate the walls of the structures in appropriate ways. The use of insulation in buildings is important both to meet comfort requirements and to reduce initial installation costs and so to reduce energy consumption. Additionally, insulation comfort conditions are provided by preventing energy consumption and condensation from occurring. Thus, moisture and mold problems that shorten the life of the structure are prevented due to condensation. Sweating occurs according to summer and winter comfort conditions and conditions of use. Sweating or condensation forms on surfaces corresponding to the temperature at which the water vapor in the air releases moisture. If the water vapor in the air does not condense on the surface of the building material, it enters the building material without sweating. At this point, as soon as the partial pressure

1 Department of Mechanical Program, Mardin Artuklu University, Mardin, TURKEY, (fatihunal@artuklu.edu.tr) https://orcid.org/ 0000-0001-6660-9984 
of the water vapor emitted to the building material is equal to the water vapor saturation pressure, it begins to condense in the inner layers. The condensation of water vapor in the air passing through the structure causes paint deterioration, mold, fungus growth, and odor. Condensation increases heat loss by increasing the total heat transfer coefficient of the material and disrupts the structure of the material [2].

When the studies in the literature are examined, Umaroğulları et al. [3] calculated some insulated and uninsulated wall sections using the WUFI®2D-3 computer program for reinforced concrete wall elements in Edirne province where the outdoor conditions change and the indoor environment is considered constant. Kavas [4] researched condensation control in terms of internal surface temperature and also studied the applicability of the sections and insulation materials, which are recommended in the thermal insulation regulation to determine whether the sections were suitable for thermal comfort.

Freezing is the condensation of water vapor in the structure causing mold, loss of adhesion, and corrosion. Water vapor passing through the structure may also carry chemicals that will damage the structure. Therefore, Akman [5] stated that in most of the demolished structures, steel reinforcements rust and the element loses its bearing quality. Bircan [6] designed a computer program and studied the process of vapor diffusion in building materials. Yuksek [7], analyzed the adequate thermal conductivity values using a reinforced concrete skeleton structure in the 3rd-degree-day zone for the determination of suitable thicknesses and condensation tests of the TS 825 by using different structural components in the vertical structural elements of the structure. Using the program designed with TS 825 method, Ozel and İlgin Beyazit [8] stated that the worst wall in terms of condensation is in the inner wall and then in the inner and middle insulated walls respectively.

Unlike other studies, this study was analyzed with software developed by Turkey's 2 nd degreedays in the region at the outer walls of buildings located in Mardin province for condensation and vapor diffusion of the TS 825 standard. For the designated structures, condensation and vapor passage were examined for each of the insulated walls from inside, middle, and outside sections. Additionally, extruded polystyrene foams with $2 \mathrm{~cm}$ and $4 \mathrm{~cm}$ thicknesses were used as insulation materials and also unreinforced concrete was used as the wall material.

\section{Humidity control with TS 825 method}

The water vapor diffused through the dry air was calculated by the Fick Law correlation $\mathrm{W}_{\mathrm{y}}$ $\left(\mathrm{kg} / \mathrm{m}^{2} \mathrm{~h}\right)$. The vapor diffusion flow rate (flow) in the wall block was calculated by Equation 1.

$$
W_{y}=\delta_{o} x \frac{p_{i}-p_{d}}{s_{d . T}^{\prime}}
$$

The vapor diffusion obtained from a non-condensing building element is given in Figure 1. The difference between the amount of moisture transported from the interface where the condensation is present and the amount of moisture transported is the amount of condensation. 


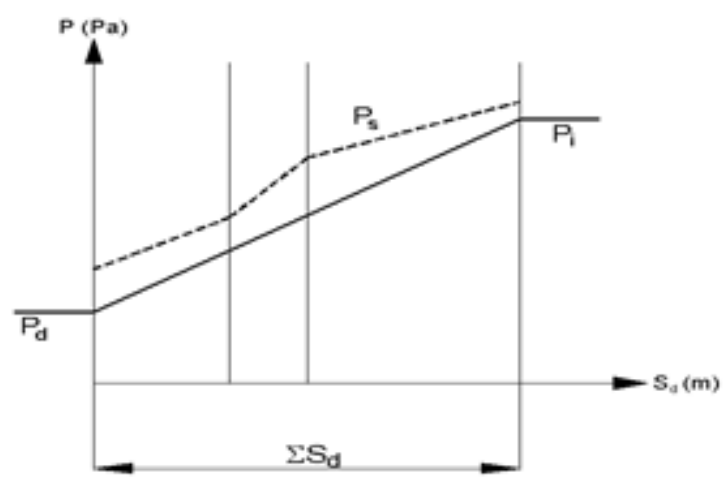

Figure 1. Vapor diffusion in a building element without condensation.

The amount of condensation can be calculated using Equation 2.

$$
W_{t}=\delta_{o}\left(\frac{p_{i}-p_{s w}}{s_{d . T}^{\prime}-s_{d, s w}^{\prime}}-\frac{p_{s w}-p_{d}}{s_{d, s w}^{\prime}}\right)
$$

Water vapor diffusion equivalent air layer thickness is calculated by Equation 3:

$$
S_{d}=\mu * d
$$

In this equation, $\mu$ expresses the water vapor diffusion resistance factor and $\mathrm{d}$ is the thickness of the layer (m).

The partial pressures were calculated by multiplying the relative humidity and saturated vapor pressure values corresponding to the internal and external temperatures. The partial pressure $\mathrm{P}(\mathrm{Pa})$ was calculated by Equation 4 and the saturated vapor pressure Ps $(\mathrm{Pa})$ was calculated by Equation 5-7.

$$
\begin{gathered}
P=P_{S} * \varphi \\
P_{S}=a\left[b+\frac{T}{100^{\circ} \mathrm{C}}\right]^{n} \\
\mathrm{~T} \leq 0^{\circ} \mathrm{C} \Rightarrow P_{s}=610,5 e^{\frac{21,875 T}{265,5+T}} \\
\mathrm{~T} \geq 0{ }^{\circ} \mathrm{C} \Rightarrow P_{s}=610,5 e^{\frac{17,269 T}{237,3+T}}
\end{gathered}
$$

For preparation and interpretation of the graph of the building shell element for the condensation period, the amount of condensation water, water vapor diffusion equivalent air layer thickness, the difference between indoor and outdoor temperature, internal and external surface temperatures and internal temperatures, saturated vapor pressure values and partial vapor pressure values should be determined [9-11]. For this purpose, the amount of heat passing through the building component was calculated with the help of Equations 8-15.

$$
q=\alpha_{d} *\left(T_{d}-T_{d y}\right)
$$




$$
\begin{gathered}
T_{1}=T_{y i}-R_{1} * q \\
T_{2}=T_{1}-R_{2} * q \\
q=\alpha_{i} *\left(T_{i}-T_{i y}\right) \\
T_{i y}=T_{i}-\frac{q}{\alpha_{i}} \\
T_{n}=T_{n-1}-R_{n} * q \\
U=U * A *\left(T_{i}-T_{d}\right) \\
\frac{1}{\frac{1}{\alpha_{i}}+\frac{d_{1}}{\lambda_{1}}+\frac{d_{2}}{\lambda_{2}}+\ldots+\frac{d_{n}}{\lambda_{n}}+\frac{1}{\alpha_{d}}}
\end{gathered}
$$

In the above equations: The internal and external surface temperatures are given as $\mathrm{T}_{\mathrm{iy}}$ and $\mathrm{T}_{\mathrm{dy}}\left({ }^{\circ} \mathrm{C}\right)$, respectively. $T_{i}$ and $T_{d}$ indicate indoor and outdoor temperatures $\left({ }^{\circ} \mathrm{C}\right)$, respectively. $R_{n}$ is defined as $1 /\left(\mathrm{d}_{\mathrm{n}} / \lambda_{\mathrm{n}}\right) . \alpha$ is the internal heat transfer coefficient $(\mathrm{W} / \mathrm{mK})$ and $\alpha_{\mathrm{d}}$ is the external heat transfer coefficient $(\mathrm{W} / \mathrm{mK})$. The total heat transfer coefficient of the structural component is given as $\mathrm{U}$ $\left(\mathrm{W} / \mathrm{m}^{2} \mathrm{~K}\right)$, the thermal conductivity coefficient of the component forming layer is given as $\lambda(\mathrm{W} / \mathrm{mK})$ and the thickness of the component forming layer is given as $\mathrm{d}(\mathrm{m})$.

\section{Condensation and diffusion examined wall models}

In this study, amounts of condensation and evaporation were calculated by using $2 \mathrm{~cm}$ and $4 \mathrm{~cm}$ extruded polyurethane insulation materials on the inner, middle, and outer parts of the unreinforced concrete wall. Schematic shapes of wall structures examined are given in this section and condensation and vapor diffusion graphics are presented for $2 \mathrm{~cm}$ insulation thickness per unit area in January for Mardin province.

\subsection{Internal insulated wall model}

The internal insulated wall model examined in the study is given in Figure 2. As seen in the figure, the effect of condensation inside the structure was examined by placing insulation material on the inner surface of the wall. When Figure 3 is examined, condensation was started at a point in the midpoints of the insulation layer and condensation occurred in more than half the area of the brick wall. 


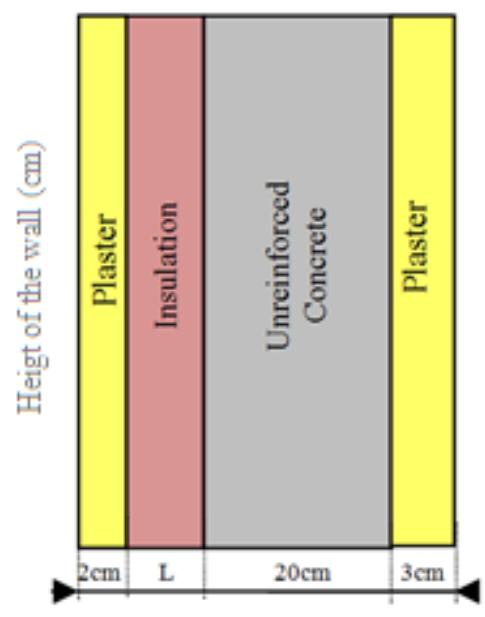

Thickness of wall components $(\mathrm{cm})$

Figure 2. Internally insulated wall.

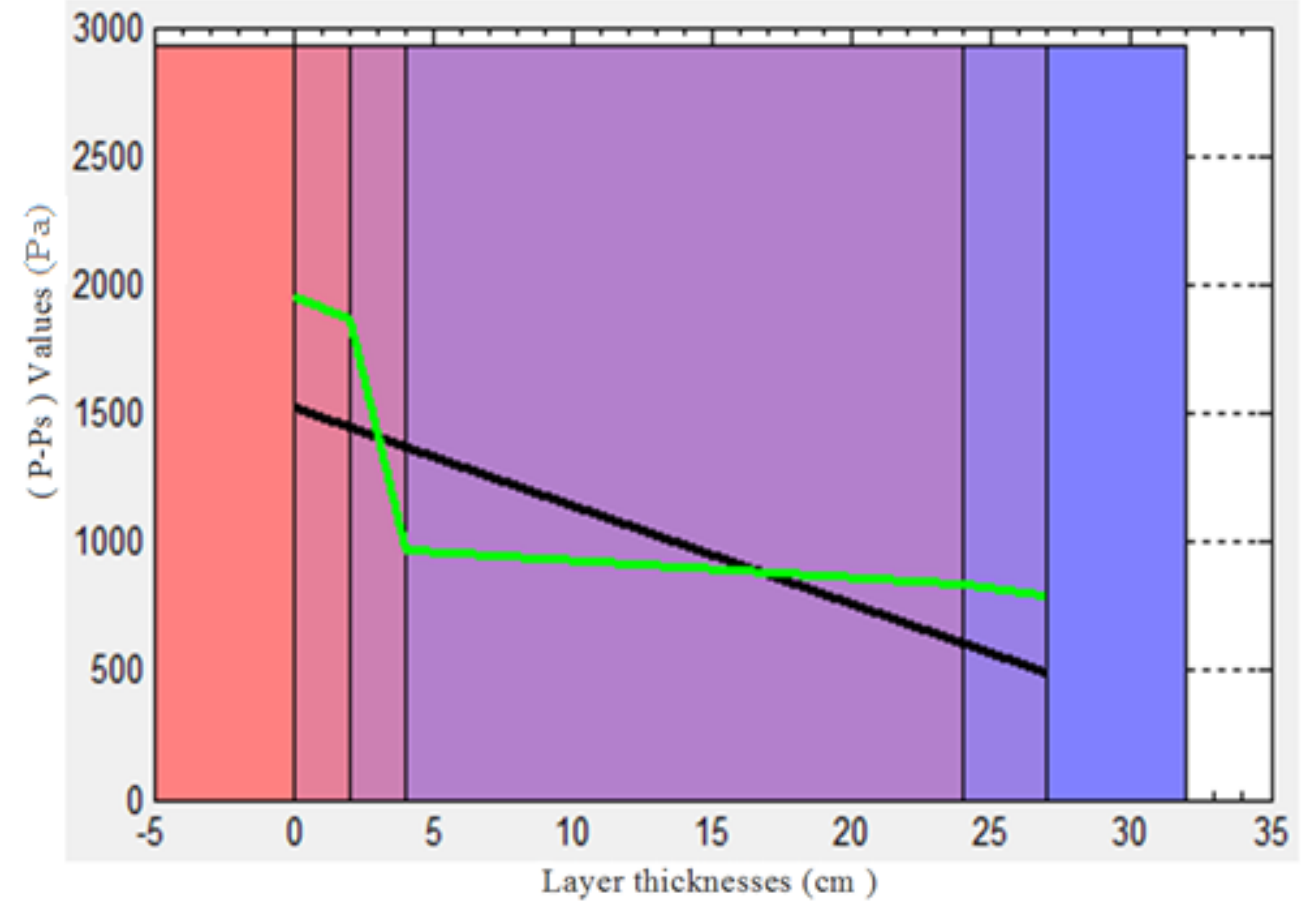

Figure 3. Vapor diffusion on $2 \mathrm{~cm}$ insulated wall from inside.

\subsection{Middle insulated wall model}

The medium insulated wall model examined in the study is given in Figure 4. As shown in the figure, the solution made as the insulation material was placed in the middle of the unreinforced concrete wall. The vapor diffusion change in the middle insulated building block is shown in Figure 5. As seen in the figure, condensation occurs in one-third of the area covering the first part of the concrete wall near the end of the insulation and the second piece of the non-reinforced concrete wall. 


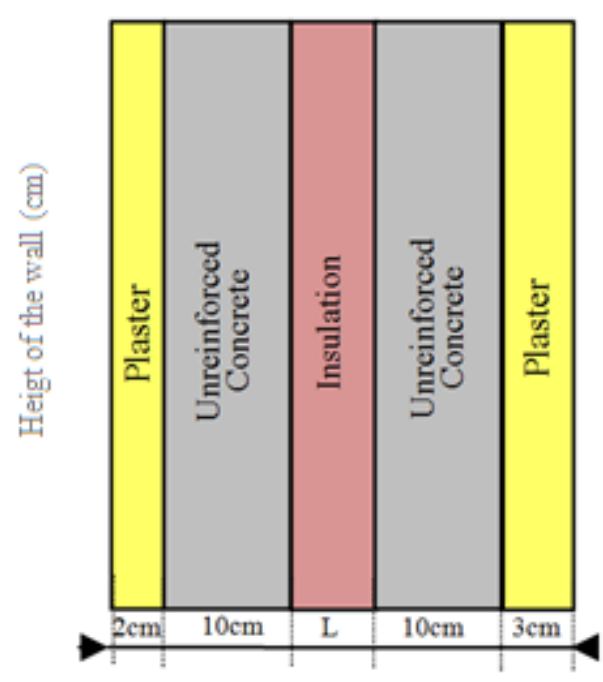

Thickness of wall components $(\mathrm{cm})$

Figure 4. Middle insulated wall.

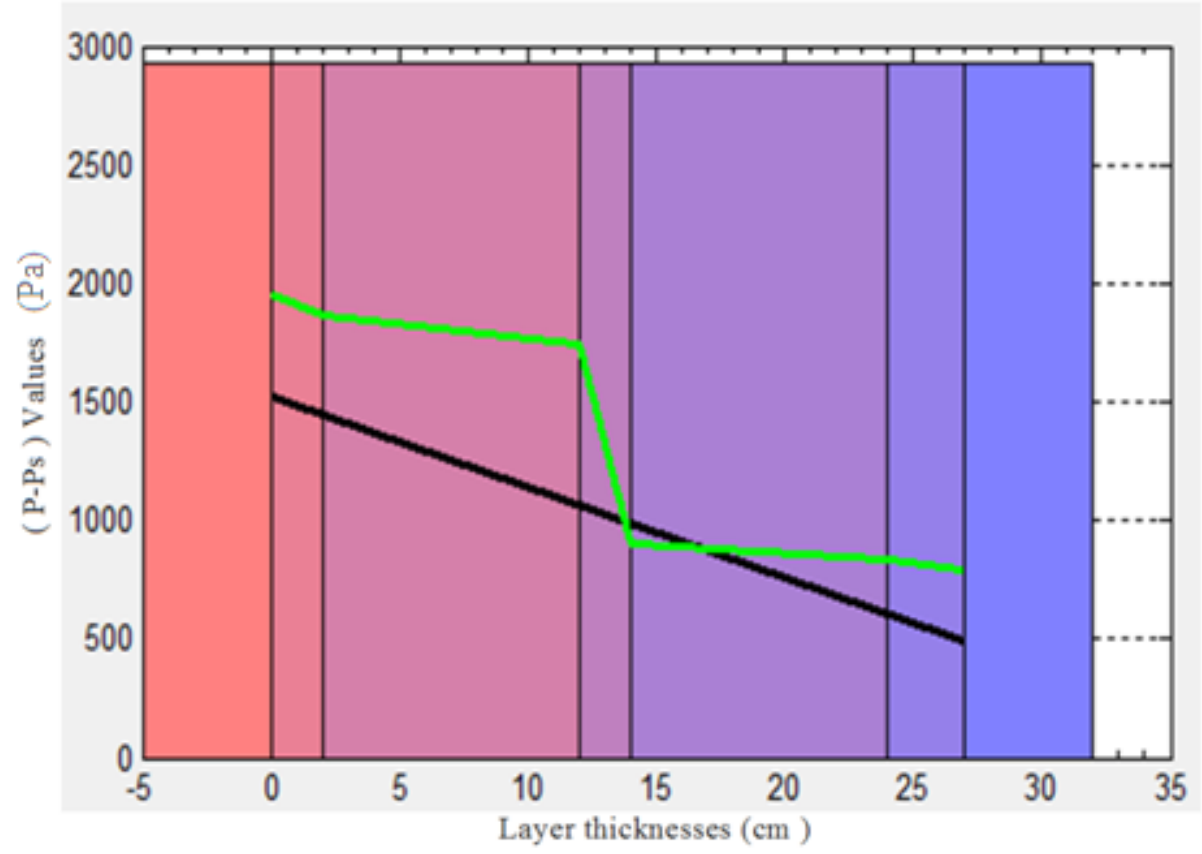

Figure 5. Vapor diffusion on $2 \mathrm{~cm}$ insulated wall in the middle.

\subsection{Externally insulated wall model}

The externally insulated wall model used in the study is given in Figure 6. As shown in the figure, the placed wall was covered with $2 \mathrm{~cm}$ of internal and $3 \mathrm{~cm}$ of external plasters. Then, a wall model was created by placing extruded polyurethane insulation materials with $2 \mathrm{~cm}$ and $4 \mathrm{~cm}$ thicknesses on the outer surface of the $20 \mathrm{~cm}$ thick unreinforced concrete wall. Figure 7 shows the variation of the vapor diffusion for the wall thickness. As seen in this figure, no condensation occurred, but there was a risk of condensation between the insulation layer and the plaster on the outer surface towards the endpoint of the insulation. 


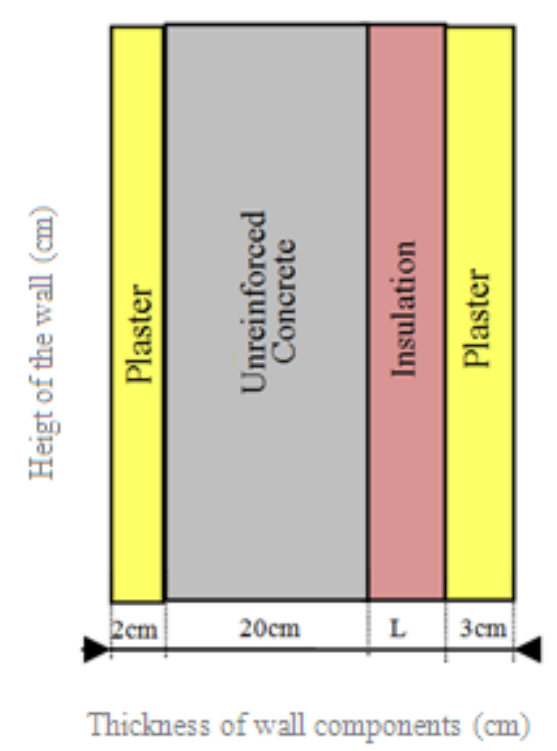

Figure 6. Externally insulated wall.

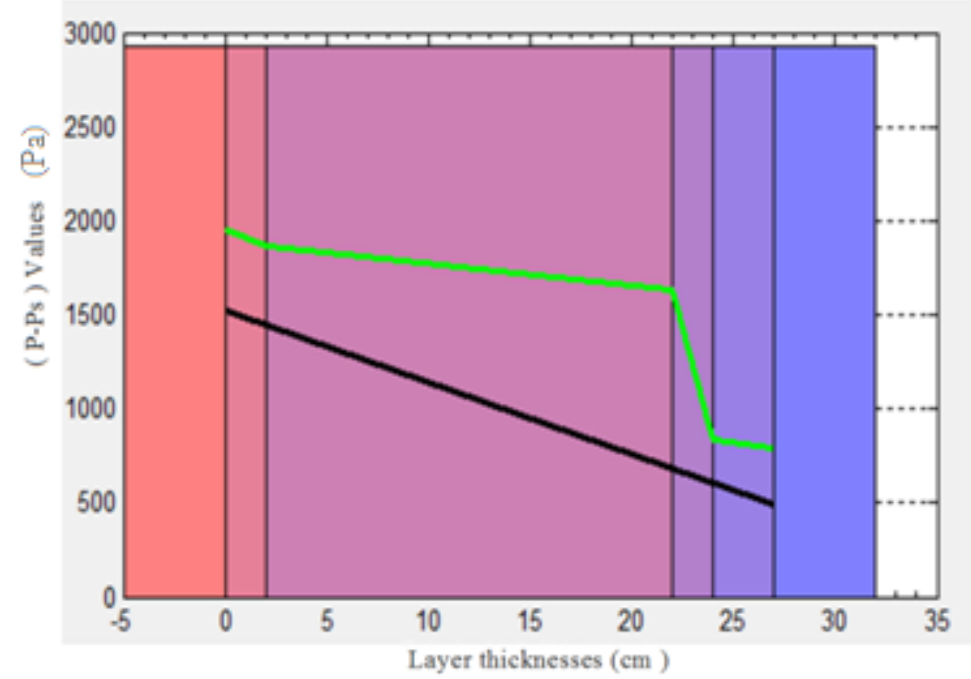

Figure 7. Vapor diffusion on external $2 \mathrm{~cm}$ insulated wall.

\section{Results and discussion}

In this study, condensation and vapor diffusion analysis of different insulation models of wall structures were performed for Mardin province, which located in Turkey's 2nd degree-days area. For this purpose, a computer program prepared according to TS 825 Standard was used. The building block was examined as a $20 \mathrm{~cm}$ wide unreinforced concrete wall, extruded polystyrene foam insulation material of $2 \mathrm{~cm}, 4 \mathrm{~cm}$, and $6 \mathrm{~cm}$ thickness, and $2 \mathrm{~cm}$ gypsum plaster from inside and $3 \mathrm{~cm}$ gypsum plaster from outside. Analyzes were made according to this building block and the results obtained were given in Table 1. 
Table 1. Condensation and evaporation amounts for 3 different insulation positioning situations with $2 \mathrm{~cm}, 4 \mathrm{~cm}$, and $6 \mathrm{~cm}$ insulation thickness for Mardin province.

\begin{tabular}{|c|c|c|c|c|}
\hline $\begin{array}{c}\text { Wall Insulation } \\
\text { Thickness }\end{array}$ & $\begin{array}{c}\text { Unreinforced } \\
\text { Concrete Wall } \\
+ \\
\text { Extruded Polyurethane Foam }\end{array}$ & $\begin{array}{c}\text { Internal } \\
\text { Insulated } \\
\text { Wall }\end{array}$ & $\begin{array}{c}\text { Center } \\
\text { Insulated } \\
\text { Wall }\end{array}$ & $\begin{array}{c}\text { Externally } \\
\text { Insulated } \\
\text { Wall }\end{array}$ \\
\hline $2 \mathrm{~cm}$ Insulated & $W_{v}\left(k g / m^{2}\right)$ & 0,088153 & 0,20538 & 0,178079 \\
\hline Wall & $W_{t}\left(k g / m^{2}\right)$ & 0,04515 & 0,14648 & - \\
\hline $4 \mathrm{~cm}$ Insulated & $W_{v}\left(\mathbf{k g} / \mathbf{m}^{2}\right)$ & 0,079482 & 0,17346 & 0,160562 \\
\hline Wall & $W_{t}\left(\mathbf{k g} / \mathbf{m}^{2}\right)$ & 0,00254 & 0,06836 & - \\
\hline $6 \mathrm{~cm}$ Insulated & $W_{v}\left(k g / m^{2}\right)$ & 0,072364 & 0,15012 & 0,146184 \\
\hline Wall & $\mathbf{W}_{t}\left(\mathbf{k g} / \mathbf{m}^{2}\right)$ & 0,00994 & 0,03751 & - \\
\hline
\end{tabular}

When the data obtained for 3 different locations and three different insulation thicknesses of the insulation model in Mardin are examined;

- In the analyzes made for the internally insulated wall model;

As a result of the calculation made by using $2 \mathrm{~cm}$ insulation material according to the TS 825 method, it was calculated that the amount of condensation water is $0.04515 \mathrm{~kg} / \mathrm{m}^{2}$ in months when the amount of condensation water can be seen all year. Moreover, the amount of water vapor carried from the wall is $0.088153 \mathrm{~kg} / \mathrm{m}^{2}$ and since this amount is $0.043006 \mathrm{~kg} / \mathrm{m}^{2}$ more than the amount of water condensed on the wall during the year, the total amount of condensed water evaporates during the year. As a result of the calculation made according to the TS 825 method by using $4 \mathrm{~cm}$ insulation material, it was calculated that the amount of condensing water was $0,00994 \mathrm{~kg} / \mathrm{m}^{2}$. Furthermore, since the amount of water vapor carried from the wall is $0.079482 \mathrm{~kg} / \mathrm{m}^{2}$, this amount is $0.07694 \mathrm{~kg} / \mathrm{m}^{2}$ more than the amount of water condensed on the wall during the year and the total amount of water condensed during the year evaporates. As a result of the calculation made according to the TS 825 method by using $6 \mathrm{~cm}$ insulation material, it was determined that the amount of condensing water was $0,00994 \mathrm{~kg} / \mathrm{m}^{2}$. Besides, since the amount of water vapor carried from the wall is $0,072364 \mathrm{~kg} / \mathrm{m}^{2}$, this amount is $0.062426 \mathrm{~kg} / \mathrm{m}^{2}$ more than the amount of water condensed on the wall during the year and the total amount of water condensed during the year evaporates. According to the results, the best insulation thickness for the internally insulated wall model was found to be $4 \mathrm{~cm}$.

- $\quad$ In the analysis made for the middle insulated wall model;

As a result of the calculation made according to the TS 825 method by using $2 \mathrm{~cm}$ insulation material, it was calculated that the amount of condensing water was $0,14648 \mathrm{~kg} / \mathrm{m}^{2}$ in the whole year. In addition to this, the amount of water vapor carried from the wall is $0,20538 \mathrm{~kg} / \mathrm{m}^{2}$ and since this amount is $0,058903 \mathrm{~kg} / \mathrm{m}^{2}$ more than the amount of water condensed on the wall during the year, the total amount of condensed water evaporates during the year. As a result of the calculation made according to the TS 825 method by using $4 \mathrm{~cm}$ insulation material, it was calculated that the amount of condensing water was $0,06836 \mathrm{~kg} / \mathrm{m}^{2}$. Furthermore, since the amount of water vapor carried from the wall is $0,17346 \mathrm{~kg} / \mathrm{m}^{2}$, this amount is $0,1051 \mathrm{~kg} / \mathrm{m}^{2}$ more than the amount of water condensed on the wall during the year and the total amount of water condensed during the year evaporates. As a result of the calculation made according to the TS 825 method by using $6 \mathrm{~cm}$ insulation material, it was determined that the amount of condensing water was $0,03751 \mathrm{~kg} / \mathrm{m}^{2}$. Additionally, since the amount of water vapor carried from the wall is $0,15012 \mathrm{~kg} / \mathrm{m}^{2}$, this amount is $0,112608 \mathrm{~kg} / \mathrm{m}^{2}$ more than the amount of water condensed on the wall during the year and the total amount of water condensed 
during the year evaporates. According to the results, the best insulation thickness for the middle insulated wall model was found to be $6 \mathrm{~cm}$.

- $\quad$ In the analysis made for the external insulated wall model;

As a result of the calculation made according to the TS 825 method by using $2 \mathrm{~cm}$ insulation material, the amount of water vapor carried from the wall throughout the year was $0,178079 \mathrm{~kg} / \mathrm{m}^{2}$. When a similar analysis was performed for $4 \mathrm{~cm}$ insulation thickness, the amount of water vapor carried from the wall was $0.160562 \mathrm{~kg} / \mathrm{m}^{2}$. In the analysis made for $6 \mathrm{~cm}$ insulation thickness, it was calculated that $0,146184 \mathrm{~kg} / \mathrm{m}^{2}$ water vapor was evaporated. According to the results, the best insulation thickness for the external insulated wall model was found to be $6 \mathrm{~cm}$.

As a result, for all three insulation thickness; The best insulation position is externally insulated and the worst insulation position is determined as the middle insulated wall model. In the evaluation made in terms of problems such as mold, moisture and paint deterioration, it was determined that the insulation position where the condensation did not occur and the natural structure of the structure did not deteriorate was an external wall model.

\section{Nomenclature}

d: Layer Thickness Forming Component $m$

D: Diffusion constant $\mathrm{cm}^{2} \mathrm{sn}^{-1}$

P: Partial Water Vapor Pressure Pa

Ps: Saturated Water Vapor Pressure Pa

$\mathrm{S}_{\mathrm{d}}$ : Water Vapor Diffusion Equivalent Air Layer Thickness m

q: Heat Transfer Amount $\mathrm{W}$

$\mathrm{T}_{\mathrm{i}}$ : Indoor Temperature ${ }^{\circ} \mathrm{C}$

$\mathrm{T}_{\mathrm{d}}$ : Outdoor Temperature ${ }^{\circ} \mathrm{C}$

$\mathrm{T}_{\text {iy: }}$ Internal Surface Temperature ${ }^{\circ} \mathrm{C}$

$\mathrm{T}_{\mathrm{dy}}$ : Outer Surface Temperature ${ }^{\circ} \mathrm{C}$

U: Total Heat Transfer Coefficient of Component $\mathrm{W}\left(\mathrm{m}^{2} \mathrm{~K}\right)^{-1}$

$\mathrm{W}_{\mathrm{y}}$ : Amount of Steam Flow (Flow) $\mathrm{kgm}^{-2}$

$\mathrm{W}_{\mathrm{t}}$ : Amount of condensation, $\mathrm{kgm}^{-2}$

$\lambda$ : Heat conduction coefficient of the material $\mathrm{W}(\mathrm{mK})^{-1}$

$\alpha_{\mathrm{i}}$ : Internal Heat Transfer Coefficient $\mathrm{W}\left(\mathrm{m}^{2 \circ} \mathrm{C}\right)^{-1}$

$\alpha_{\mathrm{d}}$ : External Heat Transfer Coefficient $\mathrm{W}\left(\mathrm{m}^{2 \circ} \mathrm{C}\right)^{-1}$

$\mu$ : Vapor diffusion resistance factor $\mu$

$\varphi$ : Relative Humidity \%

$\delta_{\mathrm{o}}$ : Steam Transmission Coefficient of air $\mathrm{kg}(\mathrm{msPa})^{-1}$

\section{References}

[1] Kallioglu, M.A., Bati, Z.A, Karakaya H., Durmuş A. (2016). Environmental and economic analysis of optimum heat insulation thickness in energy saving, European Journal of Technic,6(2),160-169

[2] Heperkan H.A., Bircan M.M., Sevindir M.K. (2001). Vapor diffusion and condensation in building materials, V. National Installation Engineering Congress and Exhibition, İzmir, TURKEY, 461-469 
[3] Umaroğulları F., Zorer Gedik, G., Mihlayanlar, E. (2011). Condensation Control of Insulated and Uninsulated Concrete Walls in the Periodic Regime: The Case of Edirne. megaronjournal, 6(1), $13-20$

[4] Kavas, E., Thermal Protected Wall Sections in Eastern Anatolia Region and Condensation Control (Erzurum Case), Master Thesis, Y1ldiz Technical University, İstanbul, TURKEY, 1997

[5] Akman, S., Building damage and repair principles, TMMOB Publications, İstanbul, TURKEY, 2000

[6] Bircan, M.M., Computer program for the examination of the vapor diffusion process in building materials and condensation calculation, Mater Thesis, Y1ldız Technical University, İstanbul, TURKEY,1999

[7] Yüksek İ., Sivacılar S.( 2017). Thermal Efficiency of Different Types Covered Walls TS 825 A Comparative Study on Conditions in Turkey. Politeknik Journal, 20 (2), 291-302

[8] Özel, M, İlgin Beyazıt, N . (2018). Condensation Analysis According to Different Location of Insulation in Wall. Dicle University Journal of Engineering Faculty(DÜMF), 9 (2), 785-794

[9] Glaser, H. (1959). Graphisches Verfahren zur Untersuchung von Diffusionsvorgangen, Kaltetechnik 11, Heft 10/59, 345-349

[10] Anon., DIN 4108, Warmeschutz im Hochbau, Beuth Verlag GmbH, Berlin, 1981

[11] Anon., TS 825 Thermal Insulation Rules in Buildings, Turkish Standard Draft, Ankara, 2008 